\title{
Хасабова К.А. \\ Особенности смысложизненных ориентаций как детерминанты процесса самоопределения в подростковом возрасте
}

Южный Федеральный Университет

(Россия, Ростов-на-Дону)

doi: 10.18411/trnio-10-2021-34

\section{Аннотация}

В статье освещена проблема детерминант процесса самоопределения в подростковом возрасте. Автор дал психологическую характеристику явлению самоопределения, представлен обзор теоретических подходов к его изучению. Исследованы особенности формирования смысложизненных ориентаций в подростковом возрасте, которые оказывают влияние на самоопределение личности.

Ключевые слова: юношеский возраст, ориентация личности, самоопределение, профессиональное самоопределение, смысложизненные ориентации, Я-Концепция, ценности, саморазвитие.

\section{Abstract}

The article deals with the problem of determinants of the process of self-determination in adolescence. The author gave the psychological characteristics of self-determination, presented a review of theoretical approaches to its study. The features of formation of sense-life orientations at the adolescent age, which influence the self-determination of a personality, are investigated.

Keywords: adolescence, personality orientation, self-determination, professional selfdetermination, sense-life orientations, self-concept, values, self-development.

Отказ подростка от детской идентичности и построение взрослой предполагает необходимость экспериментирования с собственной жизнедеятельностью, отождествления и дифференциации по отношению к различным общностям (семья, школьное сообщество и сверстники, значимые взрослые и т.д.). Именно в таком экспериментировании обретаются представления о собственных возможностях, ограничениях, ценностях, идеалах, потенциальных жизненных траекториях.

При благоприятных вариантах развития в ранней юности на основе решения задач, поставленных в предыдущем возрасте, формируется Я-концепция - достаточно развитая и относительно устойчивая система представлений о себе, основное новообразование юношеского самоопределения. Я-концепция позволяет молодому человеку выработать позитивную позицию относительно существующих в обществе и культуре норм, идеалов, ценностей, строить и реализовывать профессиональные и жизненные планы.

Процесс формирования Я-концепции, как показывают многочисленные исследования, представляется весьма драматичным. Последователь Э. Эриксона Дж. Марсиа, описывая желаемый результат решения задачи обретения идентичности - состояние достижения, указывает на иные возможные варианты состояния: диффузию (неопределенность профессиональных и жизненных ориентиров); мораторий (продолжающийся кризис, застревание в фазе принятия решений); предрешенность (принятие обязательств относительно собственного будущего под влиянием значимых других) [10]. Эти варианты могут составлять определенные этапы на пути достижения идентичности, но при неудачных попытках решения задачи - стать финишным статусом конца юношеского возраста, причиной осложнений в решении задач следующих этапов возрастного развития.

Поддержка самоопределения в перспективе культурно-исторической психологии.

Психологическая помощь молодому человеку в самоопределении предполагает решение нескольких задач:

- $\quad$ поддержка в построении адекватной картины окружающего мира;

- $\quad$ поддержка процессов самопознания, построения адекватной Я-концепции; 
- $\quad$ поддержка процессов принятия решения относительно вариантов будущего;

- поддержка в построении профессиональных и жизненных планов (перспектив);

- собственно, содействие в нахождении личного смысла решения задачи самоопределения.

При этом Н.С. Пряжников отмечает важность удержания при решении указанных частных задач, особой сверхзадачи - поддержки становления субъектности как способности к самостоятельному и осознанному решению задач самоопределения [6]. В свою очередь, это предполагает установление особого рода помогающих отношений, особого рода общностей, которые обеспечивают такое развитие.

Именно в таких общностях традиционные для поддержки самоопределения задачи переформулируются: психолого-педагогическое просвещение замещается задачей содействия в освоении средств и способов получения знаний о предметных и социальных отношениях окружающего мира; психологическая диагностика преобразуется в задачу освоения и апробации культурных средств и способов самопознания и самопонимания и т. д. Такое изменение содержания психологической поддержки требует выстраивания иной схемы взаимоотношений: отношение «эксперт - клиент» замещается партнерским отношением совместной деятельности, в котором экспертную позицию занимает подросток/ старшеклассник, а психолог выполняет функции методологической поддержки.

Изменяется основное содержание и смысл диагностической работы. Результатом традиционной диагностической работы психолога часто выступает клинический диагноз, построенный по «медицинскому» образцу. В исследовании регистрируются определенные отклонения измеряемых свойств от статистических или возрастных норм, и на этом основании диагностируемый относится к какому-либо типу. Значение такой диагностики нельзя преуменьшать, и в целом ряде случаев она является необходимой как частный момент взаимодействия в поддержке самоопределения для уточнения ситуации на основе объективных измерений. Однако цели самоисследования принципиально иные: они состоят в том, чтобы определить направления поиска жизненных и профессиональных перспектив на основе осознания собственных ценностей, карьерных ориентаций, ресурсов и ограничений. Кроме того, самоисследование имеет еще одну важную функцию: в нем старшеклассник по факту занимает субъектную позицию, принимая ответственность за результаты своей части работы - определения своих индивидуальных особенностей на основе анализа внешних оценок, результатов собственной деятельности, достижений и неудач в различных областях.

Теоретические и методологические основания для проектирования и реализации такого рода общностей, обеспечивающих решение задач развития, разработаны в рамках культурно-исторической психологии и деятельностного подхода. Прежде всего, это идея («Основной закон развития высших психических функций») Л.С. Выготского о специфических человеческих психологических процессах и формах поведения, которые развиваются и совершаются в человеческих общностях на основе знакового опосредования. Изначально существуя как процессы интерпсихологические, порождающие изменения во внутренних, «собственно психологических» процессах, они впоследствии видоизменяются во взаимодействии с последними.

Значимой для понимания становления человека представляется идея о психическом развитии как «конструировании» им функциональных органов - системных новообразований, возникающих при активном взаимодействии с окружающей предметной и социальной средой (Н.А. Бернштейн, В.П. Зинченко, А.А. Ухтомский). Эти органы, «виртуальные механизмы», включаясь в действие последовательно, не являются в своей целостности наблюдателю, но, в принципе, объективируемы [3].

Развивая идею А.А. Ухтомского в контексте обоснования гуманитарной психологии, Б.С. Братусь предлагает разделять в психологическом рассмотрении понятия «человек» и «личность», определяя последнее как функциональный орган, необходимый человеку для совершения усилия «по воспроизводству в себе человеческой сущности» [1]. Важной 
характеристикой нормальной, здоровой личности исследователь полагает стремление человека реализовать альтруистическую стратегию, строить собственные деяния исходя из безусловной ценности «Другого».

Анализируя взаимосвязь и принципиальные различия культурно-исторической концепции Л.С. Выготского и психологической теории А.Н. Леонтьева, Н.Н. Нечаев подчеркивает недостаточно раскрытый потенциал идеи Л.С. Выготского о роли знаковых форм опосредования, возникающих в ситуациях совместной деятельности, в «порождении» сознания как рефлексии «предметного» знания, образующегося во взаимодействии человека с миром [5].

Реализация указанных методологических оснований в проектировании совместной деятельности предполагает поиск знаковых моделей, позволяющих инициацию процессов самоисследования. Для отдельных подструктур личности, таких как особенности характера и темперамента, наличных интересов и склонностей, некоторых способностей, такие средства имеются и используются. Сложнее обстоит дело с пониманием личности как целостной структуры, а также с «вертикальными» характеристиками личности, относящимися к ценностно-смысловой сфере.

На наш взгляд, имеются основания для поиска средств и техник, разработанных в рамках других психологических концепций, если возможна их реинтерпретация в рамках культурно-исторической психологии и деятельностного подхода. К таким концепциям, по мнению ряда психологов, относится теория личных конструктов Дж. Келли.

Феноменологическая способность человека быть, прежде всего, субъектом собственного жизненного пути, и развиваться в существующем культурно-историческом пространстве, позволяет ему формировать смысложизненные ориентации, лежащие в основе его мотивов и поступков. Ценность анализа особенностей смысложизненных ориентаций личности в юношеском возрасте, определяется решающим значением этого возрастного этапа человека в формировании ценностной системы личности и собственного мировоззрения, открывающих дальнейшую возможность созидания внутренней, автономной системы личностных ориентиров и содержания ценностно-смысловой сферы личности. Личность развивается и вырабатывает индивидуальную направленность своего жизненного пути во взаимодействии с духовными ценностями, нравственными и социальными устоями.

В процессе изучения особенностей смысложизненных ориентаций личности, мы обратились к теоретическим представлениям отечественных и зарубежных авторов. Вслед за идеями Э. Эриксона, мы определяем период юности как этап обретения самотождественности самому себе, что позволяет сформировать качественно новые отношения человека с окружающим миром и выработать свое индивидуальное отношение к нему. Согласно представлениям Л.И. Божович, юношеский возраст характеризуется потребностью в самоопределении, которая в свою очередь, будет соединять в себе личностное, профессиональное, духовное, нравственное становление личности и позволит сформировать определенную смысловую систему, обуславливающую развитие человека на последующих этапах онтогенеза. Обращаясь к идеям Б.С. Братуся о смысловой сфере личности, мы определяем ее как единую систему, включающую мотивы, смысложизненные ориентации и ценности человека, которые находятся не в разрозненном состоянии, а образуют единую структурную и динамическую организацию способствующую созданию уникального внутреннего мира личности, и согласно представлениям Д.А. Леонтьева, смысложизненные ориентации личности - это система сознательных и избирательных связей, определяющих направленность личности, осмысленность ее выборов и оценок. Обобщая рассмотренные теоретические представления, мы полагаем, что смысложизненные ориентации определяют центральную позицию личности, которая в процессе формирования на всех возрастных этапах, придает смысл собственному существованию человека и является одной из главных духовных потребностей в любом возрасте.

В юности человек включен в переживания, связанные с его психической деятельностью, особенно сензитивен к новым открытиям, к формированию собственного 
мышления, смысложизненных ориентаций и ценностей, которые сопровождают человека на протяжении всего дальнейшего жизненного пути. Социальная ситуация развития личности в юности характеризуется в первую очередь тем, что юношам и девушкам предстоит во многом самостоятельно выйти на путь трудовой деятельности и определить своё место в обществе. Личностное самоопределение задает личностно значимую ориентацию на достижение определенного уровня в системе социальных отношений, на требования, предъявляемые к нему, т.е. задает социальное самоопределение. На основе социального самоопределения вырабатываются требования к определенной профессиональной области, осуществляется профессиональное самоопределение личности.

Самоопределение, как профессиональное, так и личностное, становится центральным новообразованием ранней юности. Это новая внутренняя позиция, включающая осознание себя как социальной единицы общества, принятие своего места в нем. Личностное самоопределение - это определение себя относительно выработанных в обществе критериев становления личности и дальнейшая действенная реализация себя на основе этих критериев. Профессиональное самоопределение - это определение человеком себя относительно выработанных в обществе (и принятых данным человеком) критериев профессионализма, но ведущее значение в профессиональном самоопределении принадлежит самой личности, её активности, ответственности за свое становление. Активность личности, предполагает ее взаимодействие с социальной средой, окружающими людьми, и развитие внутренних психических функций. При взаимодействии с окружающим миром, происходят изменения внутри компонентов смысловой сферы личности. Под влиянием, каких возможных факторов происходят эти изменения, мы рассмотрим в своей статье.

В своем исследовании мы предположили, что на формирование смысложизненных ориентаций личности в юношеском возрасте могут оказывать влияние такие факторы как: включенность в профессиональную деятельность, наличие или отсутствие партнера, состав родительской семьи и отношение к религии. Нами было проведено исследование особенностей смысложизненных ориентаций личности в юношеском возрасте. Мы предположили, что содержание смысложизненных ориентаций в юношеском возрасте отражает процесс профессионального и личностного самоопределения личности на данном возрастном этапе. Для проверки нашей гипотезы, нами были использованы следующие методы: анкетирование; рефлексивный тест-самоотчет «Кто - Я?» В.С. Мухиной; методика «Тест смысл жизненных ориентаций» Д.А. Леонтьева (СЖО); методика «Ценностные ориентации» М. Рокича; контент-анализ; статистические методы обработки эмпирических данных: критерий Н - Крускала-Уоллиса, кластерный анализ, пакет прикладных программ по статистической обработке данных SPSS.

В нашем исследовании приняли участие 106 человек, из которых 50\% юношей и 50\% девушек с разным отношением к религии, выросшие в полной или неполной родительской семье, Основная гипотеза нашего исследования, о том, что содержание смысложизненных ориентаций в юношеском возрасте отражает процесс профессионального и личностного самоопределения личности нашла подтверждение по результатам проведения эмпирического исследования. Частная гипотеза о том, что на формирование смысложизненных ориентаций личности в юношеском возрасте могут оказывать влияние такие факторы как: включенность в профессиональную деятельность, наличие или отсутствие партнера, состав родительской семьи и отношение к религии, подтвердилась частично.

Все полученные нами результаты были подвержены кластерному анализу, который позволил выделить 3 кластера.

В первый кластер, нами был условно назван «Рационалисты» вошли 32 человека (30,1\%от общего числа выборки), из которых 22 девушки, 10 юношей. Все выросли в полных родительских семьях, считают себя верующими. Цели, которые они ставят, для них наиболее реальные, что способствует гармонии между внутренним состоянием и окружающей действительностью. Готовы прикладывать усилия для получения желаемого результата. Из терминальных ценностей для них значимыми являются: ценность здоровья, гармоничных и 
духовных отношений с партнером, и счастливая семейная жизнь, в инструментальных ценностях: наличие твердой воли, умение настоять на своем, присутствие юмора и жизнерадостности. Для испытуемых данного кластера характерно наличие личностнозначимых качеств (профессионал, успешный специалист, человек науки) и ориентация на социально-значимые роли (дочь, подруга, брат, супруг).

Второй кластер, нами был условно назван «Хозяин-жизни». В него вошли 32 человека (30,1\% - от общего числа выборки), из которых 16 девушек, 16 юношей. Все выросли в полных родительских семьях, считают себя верующими, не имеют. Эти люди, четко знают, чего хотят от жизни. Они имеют четкие цели и намерения по отношению к любым делам. Рассчитывают в основном на свои силы. Считают, что все нужно держать под контролем, и только они управляют своей жизнью, и не какие социально-экономические, политические и другие факторы не смогут им помешать. Из терминальных ценностей они выделили ценности развития, продуктивных и высоких отношений с партнером, ценность ощущения комфорта и поддержки от друзей, в инструментальных ценностях отметили первостепенную значимость наличия интересной и увлекательной работы по выбранной профессии, ценность продуктивной жизни, максимально полное использование своих возможностей. Для испытуемых данного кластера также характерна ориентация на социально-значимые роли (студент, сестра, друг).

Третий кластер, был условно назван нами «Фаталисты». В него вошли 14 человек (13,2\% - от общего числа выборки), из которых 4 девушки, 10 юношей. Все выросли в неполных родительских семьях, не считают себя верующими, не имеют партнера. Испытуемые этого кластера, склонны считать, что от них в жизни ничего не зависит, что судьба к ним не справедлива. Не в их силах что-либо изменить, но при этом чувство неудовлетворенности результатом своей жизни не движет к переменам. Из терминальных ценностей превалируют ценности приятного, времяпровождения, отсутствие обязанностей и нахождение партнера, разделяющего существующий образ и стиль жизни, из инструментальных ценностей выделились: ценности умения подчинятся, созерцать прекрасное, и одаренность богатым воображением. Для данного кластера характерна выраженная маргинализация (красивая, трудолюбивый, нормальный).

Очень высокие результаты по шкале осмысленности жизни в первом и втором кластерах коррелируют с показателем наличия партнера, и составом родительской семьи, но не подтвердилось влияние фактора религиозности.

В целом, проведенное нами теоретическое и эмпирическое исследование смысложизненных ориентаций личности в юности позволило сделать следующие выводы:

1) Смысложизненные ориентации юношей и девушек на этом возрастном этапе схожи;

2) Содержание смысловой сферы личности в юношеском возрасте определяется задачами профессионального становления, поиском партнера и личностного самоопределения;

3) В юношеском возрасте смысложизненные ориентации направлены на конкретные цели как образы желаемого в будущем.

$$
\text { **** }
$$

1. Братусь Б.С. К проблеме человека в психологии // Вопросы психологии. 1997. № 5. С. 3-19.

2. Выготский Л.С. История развития высших психических функций. Собрание сочинений: в 6 т. Т. 3. М.: Педагогика, 1983.

3. Зинченко В.П. Алексей Алексеевич Ухтомский и психология (к 125-летию со дня рождения) // Вопросы психологии. 2000. № 4. С. 79-97.

4. Леонтьев Д.А. Перспективы неклассической психодиагностики // Психологические исследования: электрон. науч. журн. 2010. № 4(12). [Электронный ресурc]. URL: http://www.psystudy.ru/index.php/num/2010n4-12/353leontiev12.html (дата обращения: 10.09.2018).

5. Нечаев Н.Н. О возможности реинтеграции культурно-исторической психологии Л.С. Выготского и теории деятельности А.Н. Леонтьева // Вопросы психологии. 2018. № 2. С. 3-18.

6. Пряжников Н.С. Профессиональное самоопределение: теория и практика. М.: Академия, 2008. 
7. Франселла Ф. Новый метод исследования личности: руководство по репертуарным личностным методикам / пер. с англ. Ф. Франселла, Д. Баннистер. М.: Прогресс, 1987.

8. Hill R. Personal Constructs and Careers Exploration. Hamilton, NZ: ReConstrue; and Kindle Books, 2012.

9. Kelly G.A. The psychology of personal constructs: in 2 vols. New York: Norton, 1955.

10. Marcia J.E. Identity in adolescence // Adelson J. (ed.) Handbook of adolescent psychology. N.Y.: John Wiley, 1980.

11. Personal construct methodology /ed. By Peter Caputi ... [et al]. L.: John Wiley \& Sons Ltd, 2012.

\section{Хилюк С.О., Пичугин Д.А., Кузнецова Е.В. Причины и профилактика девиантного поведения подростков}

Уральский юридический институт МВД России (Россия, Екатеринбург)

doi: 10.18411/trnio-10-2021-35

\section{Аннотация}

В данной статье авторами приводится классификация девиантных подростков, проводится анализ форм проявления и причин возникновения девиантных форм поведения подростков. Определены субъекты, уполномоченные осуществлять профилактическую и социально-педагогическую реабилитационную деятельность с девиантными подростками и их семьями для формирования здоровой социальной среды.

Ключевые слова: профилактика, девиантное поведение, социально-педагогическая реабилитация, подростки, трудновоспитуемость.

\section{Abstract}

In this article, the authors provide a classification of deviant adolescents, analyze the forms of manifestation and causes of deviant behaviors of adolescents. The subjects authorized to carry out preventive and socio-pedagogical rehabilitation activities with deviant adolescents and their families for the formation of a healthy social environment are identified.

Keywords: prevention, deviant behavior, socio-pedagogical rehabilitation, adolescents, difficult upbringing.

На сегодняшний день, одним из актуальных вопросов по работе с несовершеннолетними гражданами в возрасте от 10 до 18 лет остается профилактика совершения ими противоправных деяний. Это обусловлено тем, что в подростковой среде часто встречаются проявления агрессии, жестокости и насилия. Чаще всего, подростковый буллинг встречается в образовательных организациях. Статистические данные свидетельствуют о том, что каждый второй подросток встречался с таким явлением как буллинг [10]. Подростки отмечают, что чаще всего буллинг проявляется в виде психологической агрессии (32\%), реже он проявляется в виде физического насилия (26,6\%). К сожалению, в статистических данных встречается и информация и о том, что подростки страдают даже от агрессии учителей (22\%). Наиболее распространенными причинами буллинга выступают: низкий социальный и экономический статус семьи подростка, национальность и неухоженность.

Последствия школьного буллинга опасны такими проявлениями как: формирование у жертвы травли комплексов, страхов, снижением интереса к образовательной деятельности, отсутствием желания посещать школу, депрессией и даже суицидом. Отпечаток буллинга в подростковом возрасте находит свое выражение и во взрослой жизни. Так, например, лица, подвергающиеся травле в школе менее уверены в себе и успешны с одной стороны жестокие и озлобленные, с другой.

Опасным является буллинг и для тех, кто выступает его зачинщиком. К сожалению, склонность к противоправному образу жизни в подростковом возрасте может повлечь за собой формирование устойчивых противозаконных и асоциальных форм поведения, которые укоренятся в сознании подростка и приведут к криминальному образу жизни в зрелом 